\title{
Mathematical Description of Sequencing Batch Reactor operation of treatment of wastewater with low concentration of organic contaminations
}

\author{
Elena Gogina*,1 \\ ${ }^{1}$ NRU Moscow State University of Civil Engineering (NRU MGSU), 129337, Jaroslavskoje sch. 26, \\ Moscow
}

\begin{abstract}
The paper is oriented towards the study of certain small wastewater-treatment plants, in particular the study of some treatment processes where the wastewater has low concentration of organic contamination. The primary goal of this paper was to obtain the characteristics of a biological treatment system which comply with the laws of enzyme kinetics. The design formulas of the Sequencing Batch Reactor with an inflow of wastewater and low concentration of organic contaminations has been obtained.
\end{abstract}

\section{Introduction}

Industrial development and the growing number of urban residents, continuously amplify the problems that appear in the sewerage systems in residential areas. At the same time, the regime of wastewater inflow of many cities and towns is characterized by an unsteady flow of wastewater, and a large irregularity coefficient. SBR (Sequencing Batch Reactor) technologies are used for both urban and industrial wastewater treatment, especially for lower or variable costs. Sequencing batch reactors are structures which involve the application of suspended sludge culture in wastewater treatment. Sequencing Batch Reactor treatment facilities are used in cities, residential areas, resorts, as well as in industries including dairy products, pulp and paper, tanneries, textile plants [1-5].

The advantages of using a Sequencing Batch Reactor are as follows:

- Sequencing Batch Reactor wastewater treatment plant can be placed on a limited area, compared to a standard aeration station, treatment takes place in one reactor, several biological treatment processes occur in one volume;

- The reactor operation cycle is adjusted to various required processes - aerobic, anoxic and anaerobic to intensify the process of deep wastewater treatment from biogenic elements. Thus, biological nitrification and denitrification can be performed to turn ammonia and organic nitrogen from wastewater into nitrates and then into gaseous nitrogen in one reactor;

\footnotetext{
* Corresponding author: goginaes@mgsu.ru
} 
- In the course of reconstruction, existing facilities can be re-equip into a Sequencing Batch Reactor [6-8].

The experience in the operation of these aerobic treatment systems in Russia has revealed their clear superiority in terms of price-performance ratio over their analogues, but they were not without drawbacks. Evolution of household chemistry has led to changes in the composition of wastewater, and this generated an increase in the content of organic compounds, varying the composition and increasing the oxidation difficulty. Changes that occur in the composition of wastewaters from permanent residence single-family homes, usually led to a significant efficiency decline of any biological treatment system. If speaking about wastewater treatment plants in small towns and villages, there is usually a different situation. The low cost of drinking water leads to the fact that residents of small towns use fresh water in an improvidently manner, so the wastewater entering treatment plant is characterized by low concentrations of contaminations [9-13]. Unfortunately, there are difficulties in treating wastewater when the ratio between the concentration of organic contaminations in the wastewater and biogenic elements does not correspond to the standard biological process that prevails in most treatment plants. Therefore, the main goal of this study was to conduct a laboratory-scale experiment with the simulation of a Sequencing Batch Reactor, which was set to several modes of operation for the treatment of low concentrated wastewater [14-17].

\section{Materials and Methods}

The study consisted of three parts. The tests were carried out at the laboratory bench of the Scientific Educational Center "Water Supply and Water-Removal" of the Water Supply and Water-Removal Department of the Moscow State University of Civil Engineering. A 30 litres Plexiglass column was used in the biological reactor operation. In order to find the most suitable modes of operation, outlets were mounted in this column at different heights. The reactor operation mode included following cycles: filling the system with wastewater; sludge mix aeration; mixing; then aeration and mixing; sedimentation of the purified water; drainage of purified water; drainage of excess activated sludge. Wastewater treatment time varied from 8 to 24 hours. The main data of the experiment are shown in Table 1.

Table 1. The main data of the experiment

\begin{tabular}{|l|c|c|c|c|}
\hline \multirow{2}{*}{ Parameters } & Incoming & \multicolumn{3}{c|}{ Treated drain liquids } \\
\cline { 3 - 5 } & waste liquid & 24 hours & 16 hours & 8 hours \\
\hline \multirow{2}{*}{$\mathrm{BOD}_{5}, \mathrm{mg} / \mathrm{L}$} & 110 & 7.6 & 9.7 & 10 \\
& & & & \\
\hline Ammonium nitrogen, mg/L & 28 & 1.2 & 7.7 & 9.4 \\
\hline Nitrites, mg/L & - & 0.36 & 2.28 & 1.78 \\
\hline Nitrates, mg/L & - & 5.2 & 7.9 & 9.3 \\
\hline
\end{tabular}




\section{Interpretation}

Based on the practical solution and experience in calculating such structures abroad, a formula was chosen to calculate the specific oxidation rate of organic contaminations considering activated sludge recirculation, which has number (1) in this section [18-20].

$$
r=\frac{L_{e n}-L_{e x}}{R * a(1-S) t}
$$

where $\mathrm{r}$ - specific oxidation rate of organic contaminations, $\left(\mathrm{mgBOD}_{5} / \mathrm{g}_{\text {ash-free basis }} / \mathrm{h}\right)$;

Len $-\mathrm{BOD}_{5}$ in the waste liquid entering the treatment plant $\left(\mathrm{mgBOD}_{5} / \mathrm{l}\right)$;

Lex $-\mathrm{BOD}_{5}$ in the purified liquid, $\left(\mathrm{mgBOD}_{5} / \mathrm{l}\right)$;

$\mathrm{R}$ - Recycling coefficient calculated as Qr/Qpost ratio;

$\mathrm{Qr}$ - water volume, $\left(\mathrm{m}^{3}\right)$, Qpost - return sludge volume, $\left(\mathrm{m}^{3}\right)$;

a - Sludge dose which was constantly kept at $2.1(\mathrm{~g} / \mathrm{l})$;

$\mathrm{S}$ - Ash content of activated sludge 0.3 ;

$\mathrm{t}$ - Sludge mix residence time in the reactor, (h).

To calculate the activated sludge load $-\mathrm{q},\left(\mathrm{mgBOD}_{5} / \mathrm{g}_{\text {ash-free basis }} /\right.$ day) a formula was used considering the recirculation of activated sludge.

$$
q=\frac{24(\text { Len }- \text { Lex })}{R \cdot a(1-S) t}
$$

Len $-\mathrm{BOD}_{5}$ in the waste liquid entering the treatment plant $\left(\mathrm{mgBOD}_{5} / \mathrm{l}\right)$;

$\mathrm{Lex}-\mathrm{BOD}_{5}$ in the purified liquid, $\left(\mathrm{mgBOD}_{5} / \mathrm{l}\right)$;

$\mathrm{R}$ - Recycling coefficient calculated as Qr/Qpost ratio;

$\mathrm{Qr}$ - water volume, $\left(\mathrm{m}^{3}\right)$, Qpost - return sludge volume, $\left(\mathrm{m}^{3}\right)$;

a - Sludge dose which was constantly kept at $2.1(\mathrm{~g} / \mathrm{l})$;

$\mathrm{S}$ - Ash content of activated sludge 0.3 ;

$\mathrm{t}$ - Sludge mix residence time in the reactor, (h).

Having made the calculation, we got the following values, which are given in Table 2.

Table 2. The calculation results

\begin{tabular}{|c|c|c|}
\hline $\begin{array}{c}\text { Sludge mix residence } \\
\text { time in the reactor, } \mathrm{h} .\end{array}$ & $\begin{array}{c}\mathrm{BOD}_{5} \text { specific oxidation rate, } \\
\mathrm{mgBOD}_{5} / \mathrm{g}_{\text {ash-free basis }} / \mathrm{h}\end{array}$ & $\begin{array}{c}\text { Organic contaminations sludge load, } \\
\mathrm{mgBOD}_{5} / \mathrm{g}_{\text {ash-free basis }} / \text { day }\end{array}$ \\
\hline 24 & 4.03 & 159.5 \\
\hline 16 & 6.2 & 223.1 \\
\hline 8 & 14.4 & 519.5 \\
\hline
\end{tabular}

The diagrams clearly show specific oxidation rates and loads on activated sludge (Fig.1). 


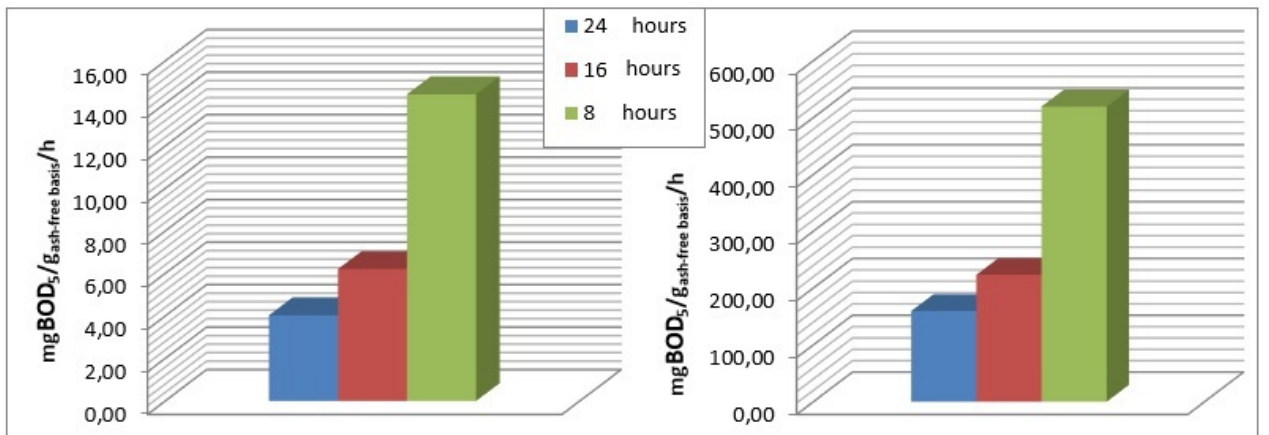

Fig. 1. Diagrams of distribution (left) of the specific rate of organic contaminations oxidation; (right) activated sludge load distribution of organic contaminations diagram.

The diagrams show that the load on activated sludge and the specific rate of oxidation of organic contaminations is minimal in the 24-hour reactor mode of operation.

The efficiency of wastewater treatment in different operating modes is presented in Table 3.

Table 3. The efficiency of wastewater treatment in different operating modes

\begin{tabular}{|l|c|c|c|}
\hline \multirow{2}{*}{$\begin{array}{c}\text { Parameters } \\
\text { in \% to the incoming water }\end{array}$} & \multicolumn{3}{|c|}{ Treated drain liquids } \\
\cline { 2 - 4 } & 24 hours & 16 hours & 8 hours \\
\hline BOD $_{5}$ & 93 & 91.2 & 90.9 \\
\hline Ammonium nitrogen & 95.7 & 72.3 & 66.4 \\
\hline
\end{tabular}

The table below shows that the most efficient mode of operation of the wastewater treatment plant is the 24-hour cycle.

Figures 2, 3, 4 show the dependencies of the BOD specific oxidation rates in treated wastewater in different operation modes.

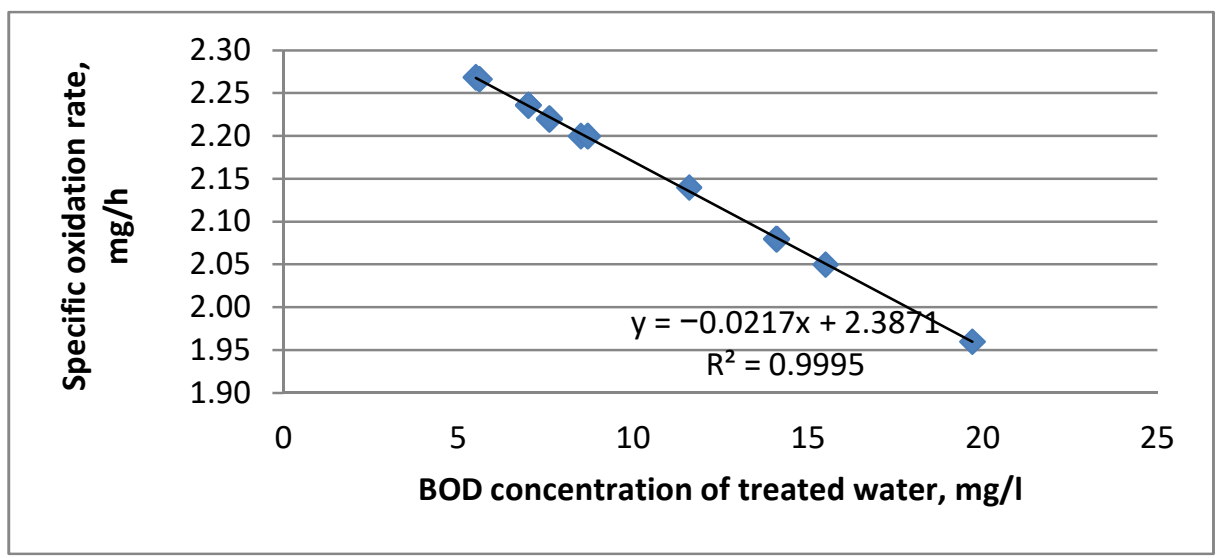

Fig. 2. Dependence of the specific oxidation rate on the BOD in treated wastewater in the 24-hour reactor operation mode. 


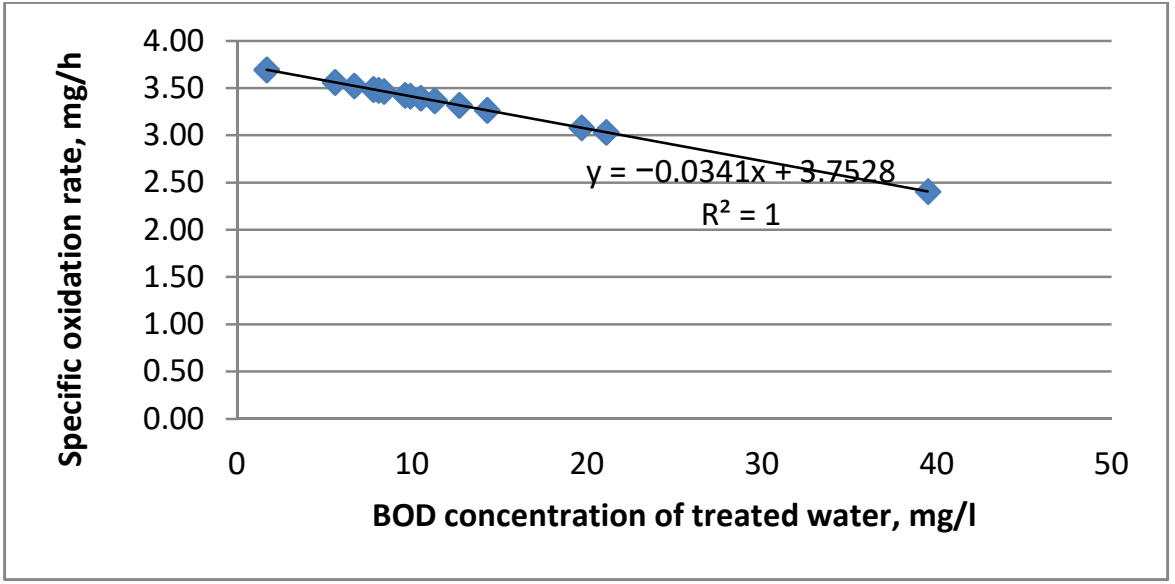

Fig. 3. Dependence of the specific oxidation rate on the BOD in treated wastewater in the 16-hour reactor operation mode.

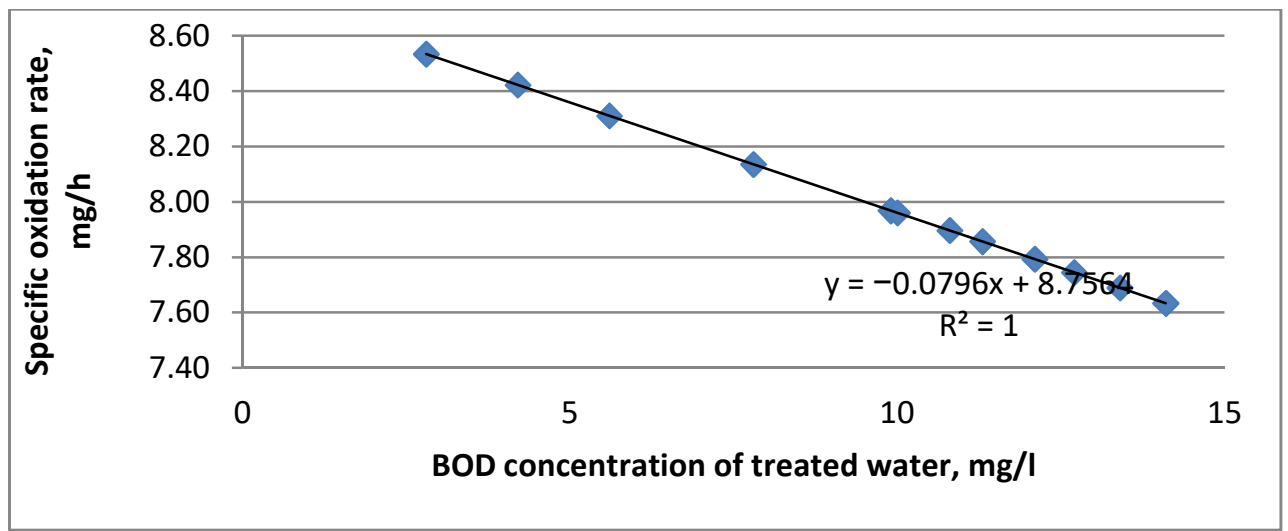

Fig. 4. Dependence of the specific oxidation rate from BOD of treated wastewater in the 8-hour reactor operation mode.

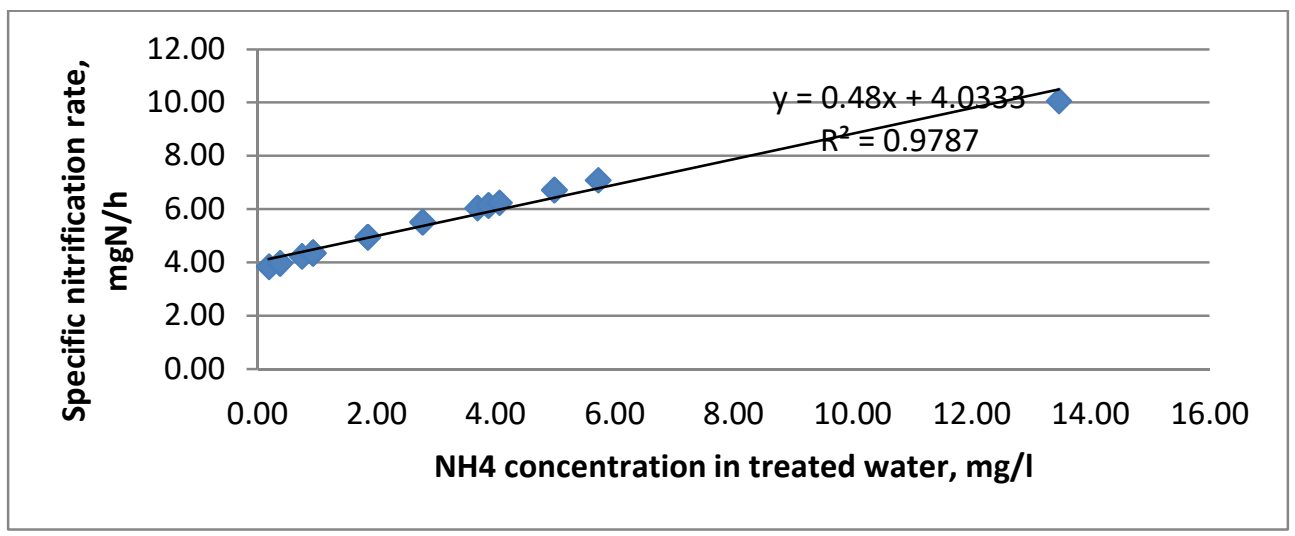

Fig. 5. Dependence of the specific nitrification rate on the BOD in treated wastewater in the 24hour reactor operation mode. 
The above diagrams show that the decrease in the BOD concentration in treated water is proportional to the decrease in specific oxidation rate, and this dependence can be described by the linear equation.

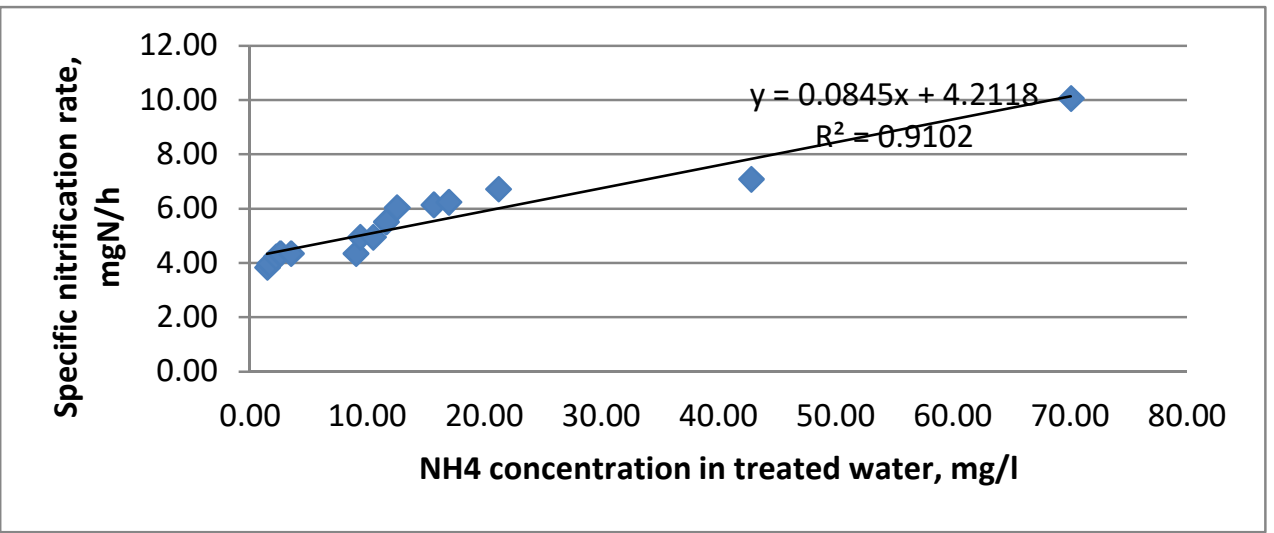

Fig. 6. Dependence of the specific oxidation rate on ammonium nitrogen concentration in treated wastewater in the 16-hour reactor operation mode.

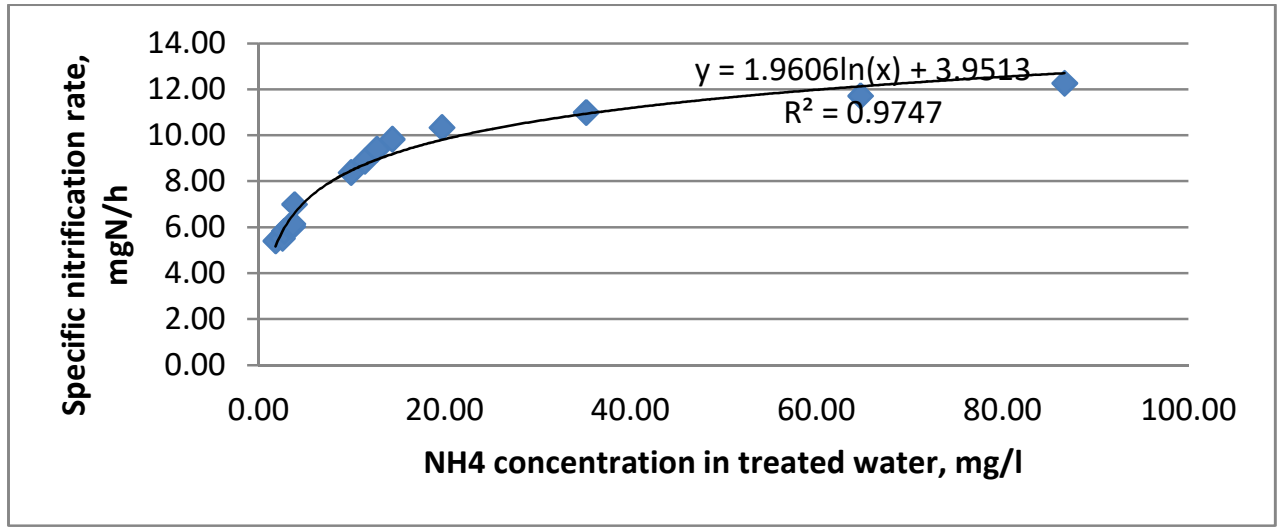

Fig. 7. Dependence of the specific oxidation rate on ammonium nitrogen concentration in treated wastewater in the 8-hour reactor operation mode.

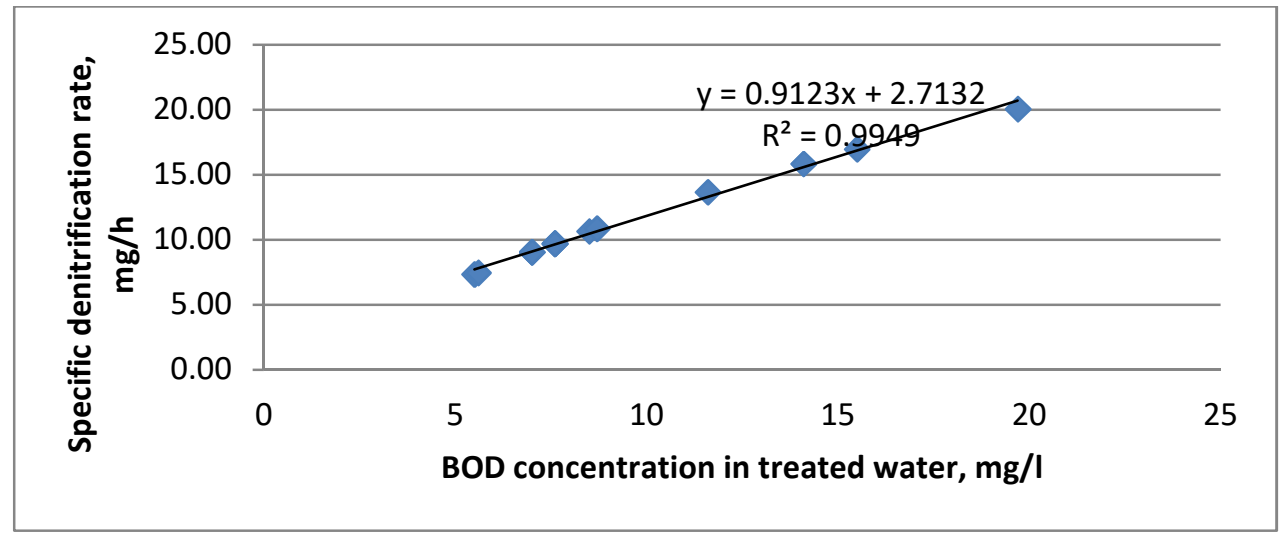

Fig. 8. Dependence of the specific oxidation rate on the BOD in treated wastewater in the 24-hour reactor operation mode. 


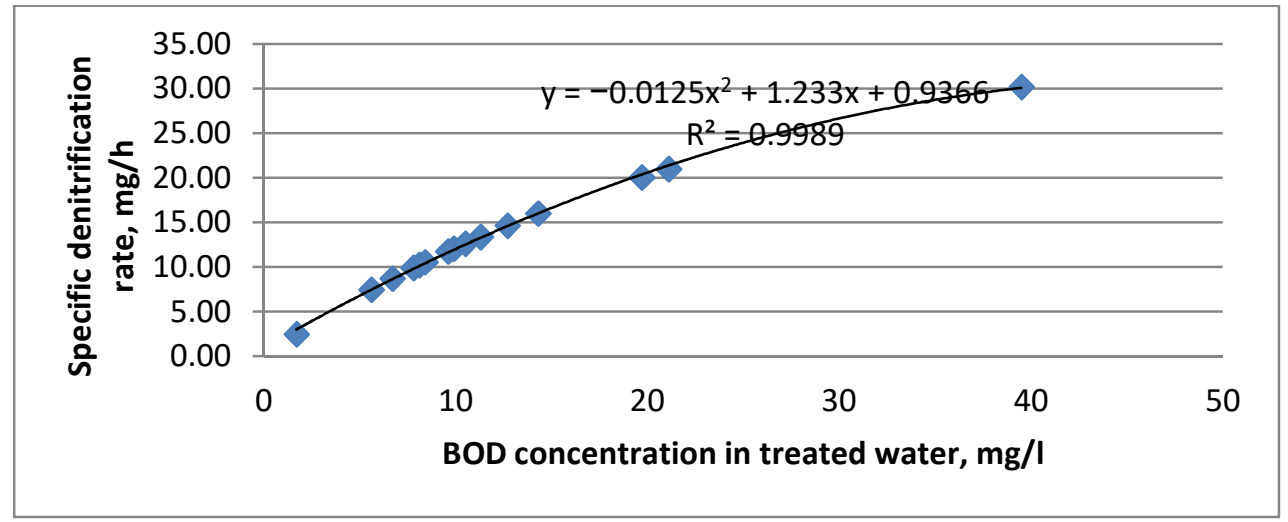

Fig. 9. Dependence of the specific oxidation rate on the BOD in treated wastewater in the 24-hour reactor operation mode.

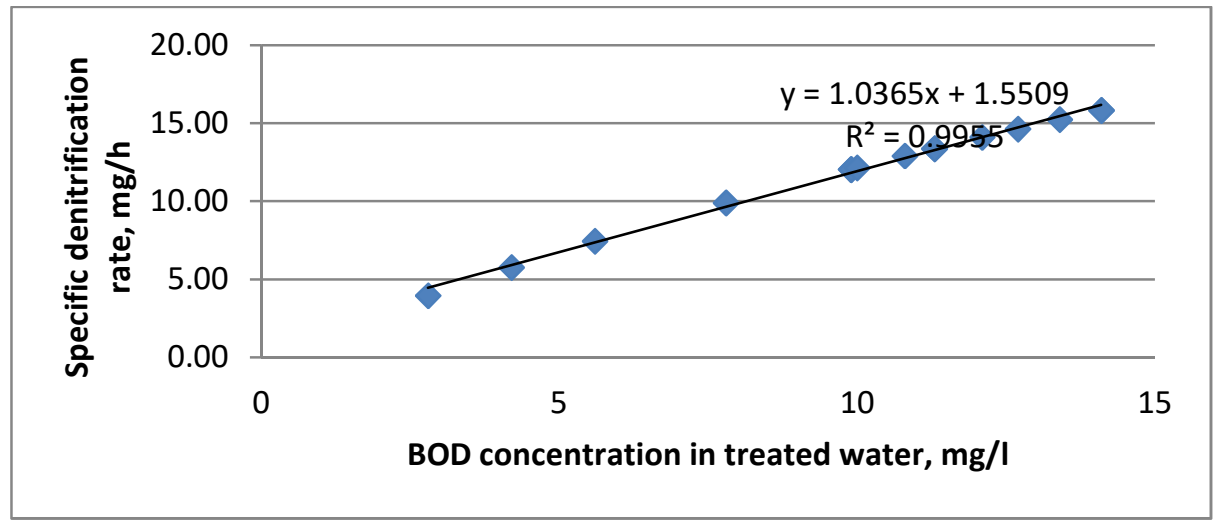

Fig. 10. Dependence of the specific oxidation rate on the BOD in treated wastewater in the 8-hour reactor operation mode.

The diagrams in Figures 8, 9, 10 show the dependence of denitrification specific rate on BOD in treated water in three modes of reactor operation, from which it is possible to conclude that the results are subordinated to linear equations. The equations show that the lower the concentration of $\mathrm{BOD}$, the lower the specific denitrification rate.

The diagrams in Figures 5, 6, 7 show the dependence of the specific oxidation rate on ammonium nitrogen concentration in treated wastewater in various reactor operation mode. The higher the concentration of ammonium nitrogen in the treated water, the higher the specific nitrification rate. 


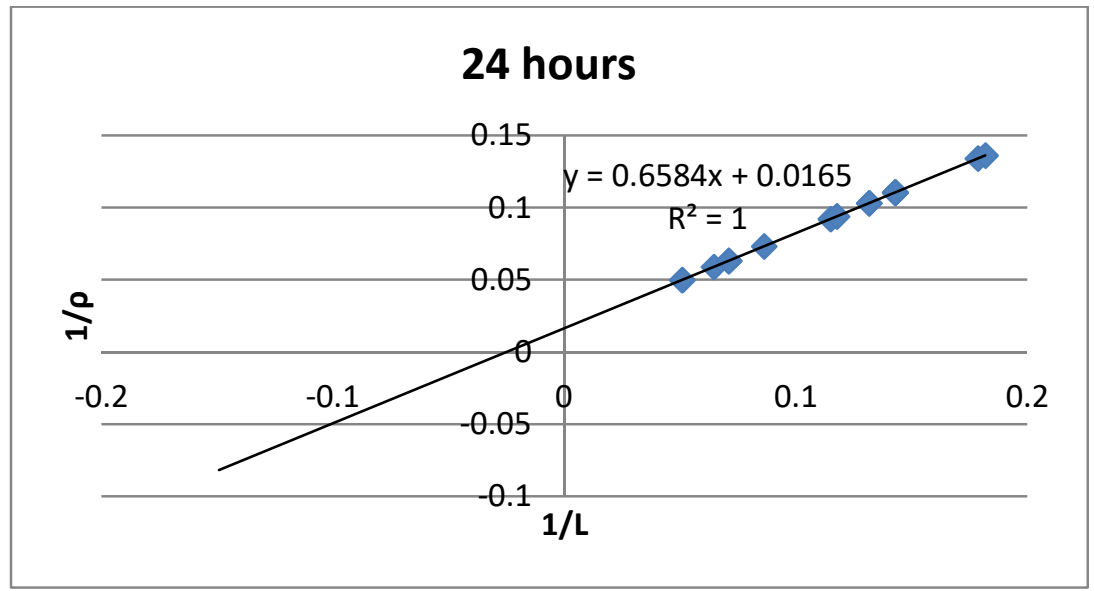

Fig. 11. The Diagram of the dependence of inverse values of organic contamination oxidation rate on inverse value of BOD5 contamination concentration

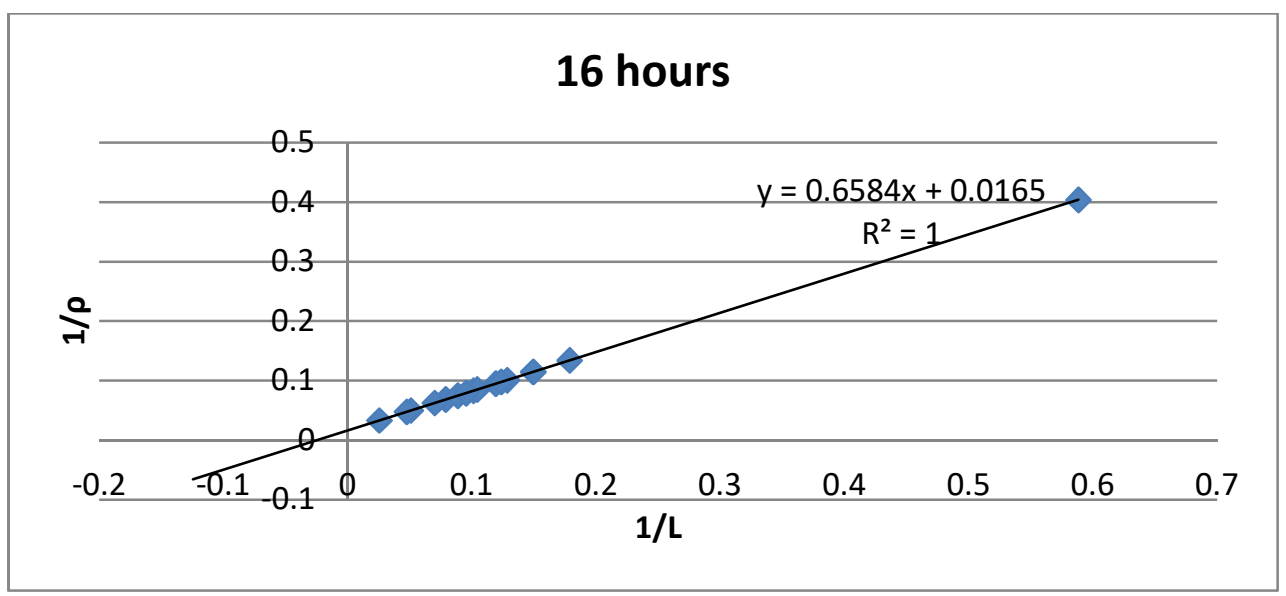

Fig. 12. The Diagram of the dependence of inverse values of organic contamination oxidation rate on inverse value of BOD5 contamination concentration

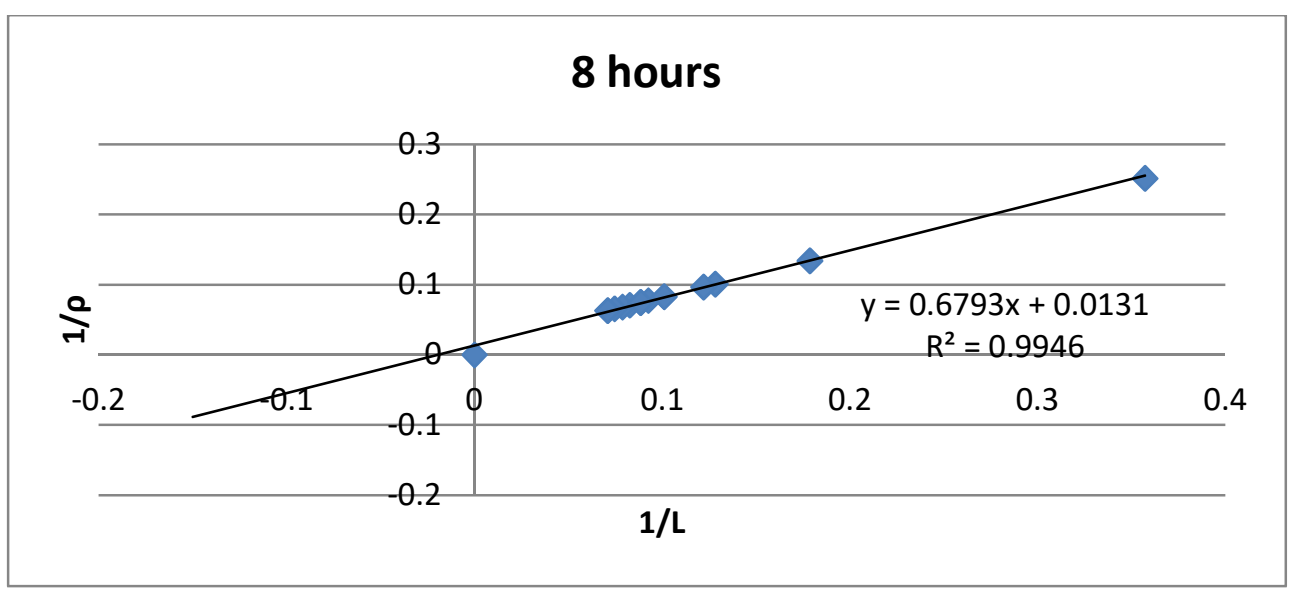

Fig. 13. The Diagram of the dependence of inverse values of organic contamination oxidation rate on inverse value of BOD5 contamination concentration 
All obtained diagrams are generally subject to the law of enzyme kinetics, and this is explained by the fact that their speed is proportional to the substrate concentration: it increases to a certain level.

Based on the Michaelis-Menten provisions of enzyme kinetics, diagrams of inverse values have been constructed, which indicate that the experiment conducted and the results obtained fully comply with the laws of enzyme kinetics, despite the low concentrations of organic contaminations and nitrogen compounds in the incoming wastewater. Figures 11-13 present diagrams of the dependence of inverse values of organic contamination oxidation rate on inverse value of BOD5 contamination concentration $1 / \mathrm{V}=f(1 / \mathrm{Lex})$. Table 4 shows the obtained values of the Michaelis-Menten constants - Vmax and $\mathrm{km}$.

Table 4. The obtained values of the Michaelis-Menten constants

\begin{tabular}{|c|c|c|}
\hline Stages & $V_{\max }, \mathrm{mgBOD} /(\mathrm{g} \cdot \mathrm{h})$ & $k_{m}$ \\
\hline 24 hours & 60.6 & 40 \\
\hline 16 hours & 60.6 & 40 \\
\hline 8 hours & 76.3 & 52.6 \\
\hline
\end{tabular}

With the results obtained, we will calculate the oxidation rates of organic impurities using the obtained maximum values of the oxidation rate from the Michaelis-Menten constant for each process separately:

$$
\begin{aligned}
& V_{24}=\frac{V_{\max } \cdot S}{k_{m}+S}=\frac{60 \cdot L_{e x}}{40+e x} \\
& V_{16}=\frac{V_{\text {max }} \cdot S}{k_{m}+S}=\frac{60 \cdot L_{e x}}{40+L_{e x}} \\
& V_{8}=\frac{V_{\max } \cdot S}{k_{m}+S}=\frac{76,3 \cdot L_{e x}}{52,6+L_{e x}}
\end{aligned}
$$

In Figure 14 one can see that the diagrams are parallel to each other and are described by the same equation, which confirms the statement about identical kinetic dependencies in these modes of the plant operation. The diagram of the 8-hour plant operation mode differs in Vmax position, however the Michaelis-Menten constant is much higher. This allows us to say that in this system the maximum oxidation rate of contaminations is achieved faster than in the others. 


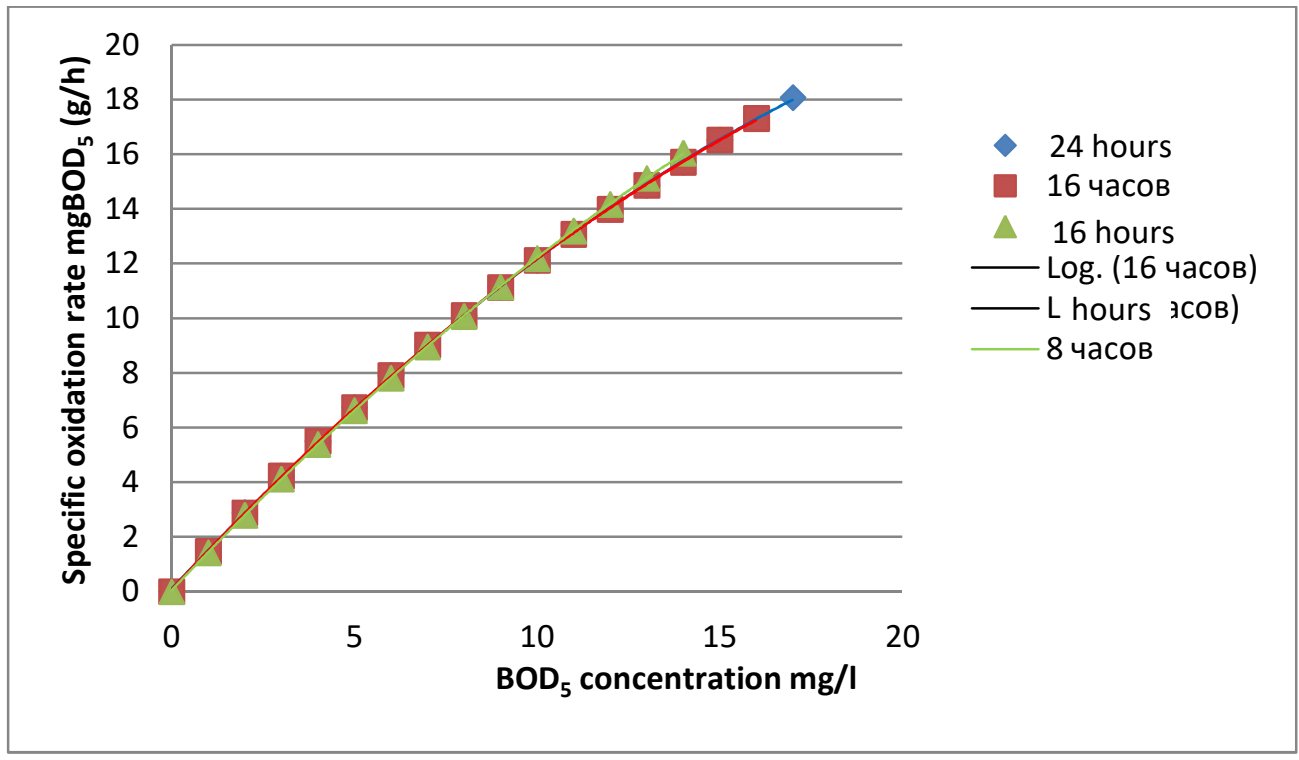

Fig. 14. Dependence of organic contaminations specific oxidation rate on $\mathrm{BOD}_{5}$ concentration.

\section{Conclusions}

The conducted study of the Sequencing Batch Reactor operation has shown possibility of its application for biological treatment of wastewater with low concentration of organic contaminations. The most suitable modes of operation of the batch reactor with low concentrated wastewater with the most efficient purification have been determined. Mathematical dependences for description of wastewater treatment process in the Sequencing Batch Reactor have been received, allowing to carry out calculation of reactors when designing treatment facilities.

\section{References}

1. N. Høiby, APMIS, 125, 272-275 (2017)

2. C. R. Kokare, S. Chakraborty, A. N. Khopade, K. R. Mahadik, Indian J Biotechnol. 8, 159-168 (2009)

3. A. Kulakov, N. Makisha, MATEC Web of Conferences, 112, 10019 (2017)

4. T. George, B. Franklin, S. David, Wastewater Engineering Treatment and Reuse (2003)

5. I. M. Panova, I. Noiberg, Ecology Production, 6, 58-61 (2014)

6. Sequencing Batch Reactor [Electronic resource] // IWA the International water Association Publishing. URL: https://www.iwapublishing.com/news/sequencing-batchreactor.

7. R. F. Poltak, Sequencing Batch Reactor Design and Operational Considerations (2005)

8. L. Hernández et al. Water, 2, 155-169 (2010)

9. Primer for Municipal Wastewater Treatment Systems. United States Environmental Protection Agency, 2004. EPA 832-R-04-001 
10. Summary report SBR. United States Environmental Protection Agency, 1986. EPA/625/8-86/011

11. E. F. Barth, Implementation of Sequencing Batch Reactors for municipal treatment. (1983)

12. T. Ha Quan, E. Gogina, E3S Web Conf., 97, 01017 (2019)

13. T. Ha Quan, E. Gogina, Vestnik MGSU, 5, 589-602 (2019)

14. C. Lenore, G. Arnold, E. Andrew, Standard Methods of the Examination of Water and Wastewater (1999)

15. Unified methods for Examination of Water Quality. Part 1 - Methods of chemical analysis of water. Vol. 1 - Basic methods. Moscow, Council for Mutual Economic Assistance Publ., 1987; 1244. (rus.).

16. M. Henze, W. Gujer, T. Mino, M. Loosdrecht, IWA Publishing in its Scientific and Technical Report series (2015)

17. Biological Nutrient Removal Processes. Operation of Municipal Wastewater Treatment Plants. Water Environment Federation, 2007. Vol. 2.

18. Nitrification Denitrification. Michigan Department of Environmental Quality Operator Training and Certification Unit.

19. S. Morling, Vatten, 64, 121-128 (2008)

20. X. Song et al. AIP Conference Proceedings, 040021 (2017) 